\title{
Validation of Age at Puberty of Nigerian Bitches
}

\author{
Obudu Christopher Ese*, Awodi Daniel Adejo, Ubah Simon Azubuike, \\ Columbus Philemon Kwinjoh, Abah Kenneth Owoicho
}

Department of Theriogenology, Faculty of Veterinary Medicine, University of Abuja, Abuja, Nigeria

Email address:

christopher.obudu@uniabuja.edu.ng(O.C. Ese)

${ }^{*}$ Corresponding author

\section{To cite this article:}

Obudu Christopher Ese, Awodi Daniel Adejo, Ubah Simon Azubuike, Columbus Philemon Kwinjoh, Abah Kenneth Owoicho. Validation of Age at Puberty of Nigerian Bitches. Animal and Veterinary Sciences. Vol. 6, No. 1, 2018, pp. 6-11. doi: 10.11648/j.avs.20180601.12

Received: October 25, 2017; Accepted: November 17, 2017; Published: January 18, 2018

\begin{abstract}
The age at puberty of Nigerian dogs around the Federal Capital Territory (FCT), Abuja was determined in order to validate earlier reports from other parts of Nigeria and to provide additional information for canine reproductive research. 16 pre-pubertal female dogs were purchased from different dog markets and households within the FCT. They were housed in cages in groups of four and allowed to acclimatise for two weeks, during which time they were treated against external and internal parasitic infections until they were clinically free from disease. They were also vaccinated against common diseases such as rabies, distemper, leptospirosis, parvo and hepatitis using standard vaccines and fed twice daily with household meals. They were then observed daily for the onset of puberty through behavioural changes, haematology and vaginal cytology. All the dogs attained puberty between eight and thirteen months of age. Dog owners are therefore advised to be properly guided to prepare for the bloody discharge that is associated with onset of reproductive cyclicity. There is also need for patience as many dogs in this environment attain puberty at a later age than exotic breeds.
\end{abstract}

Keywords: Dog, Reproduction, Puberty, Nigeria

\section{Introduction}

Dogs are the most primitive companion of man and have been domesticated as early as 8,000 BC $[1,2,3]$. They are used for several purposes including sports, hunting, guide, guard, companionship, pets, recreational purposes, biomedical research and models to study human diseases [4]. This is because they share many biomedical and physiological characteristics with human. In addition, they are important sources of animal protein in some local communities in Nigeria, some parts of Asia and other parts of the word. As useful as they are, there is a dearth of information on their reproductive biology and hence the reproductive potential of this valuable animal has not been fully harnessed [5]. The reproductive potential of an animal is measured by considering its reproductive parameters such as age at puberty, oestrus cycle, interoestrus interval, gestation length, litter size, sex ratio, birth weight, period of first oestrus after gestation, growth rate of neonates and neonatal mortality [6].

Puberty can be defined as a maturational process of the hypothalamic-pituitary-gonadal axis, which starts during the foetal period and reaches a completely mature state in adolescence. This endocrine unit is fully active in the foetal period, but undergoes suppression during infancy followed by reactivation of the axis at the onset of puberty [7].

There is a wide variation in the age at puberty of domestic dogs; that is, the age at which they attain sexual maturity and have their first reproductive or oestrus cycle [8]. It begins at about 6-12 months of age for both male and female [9] but may be delayed until 24 months in some large breeds [10]. According to the International Livestock Research Institute (2015), domestic canines reach sexual maturity (puberty) between the ages of 6 to 12 months for both males and females, although this can be delayed until up to two years of age for some large breeds. In the bitch, puberty is recognized when the first signs of proestrus occur [11].

However, there are no known reports on the age at puberty of Nigerian local dogs. This study was therefore embarked upon in order to document and validate the age at puberty (AP) and hence onset of reproductive activity of Nigerian local bitches in this environment, provide reliable 
information for prospective breeders and researchers and add to the body of existing knowledge.

\section{Materials and Methods}

\subsection{Study Location}

This study was conducted in Gwagwalada in Gwagwalada Area Council of the Federal Capital Territory (FCT). It is located between latitude $8^{\circ}$ and $9^{\circ} 25^{\prime \prime}$ North of the equator and longitude $6^{\circ} 45^{\prime \prime}$ and $7^{\circ} 45^{\prime \prime}$ East of the Greenwich Meridian. The Territory covers an area of $1,043 \mathrm{~km}^{2}$ and falls within the semi-seasonal equatorial climate zone with associated contrasting wet and dry periods [12]. The rainy season begins from April and ends in October, while daytime temperature reaches $28^{\circ} \mathrm{C}$ to $30^{\circ} \mathrm{C}$ and night time temperature of $22^{\circ} \mathrm{C}$ to $23^{\circ} \mathrm{C}$. During the dry season, daytime temperature can soar as high as $40^{\circ} \mathrm{C}$ and night time temperature can drop as low as $12^{\circ} \mathrm{C}$ [12]. The high altitude and undulating terrain of the FCT acts as a moderating influence on the weather of the territory [13].

\subsection{Animal Management}

Sixteen (16) pre - pubertal female dogs aged between 3 months to 5 months were purchased from local markets and households in Gwagwalada and environs. They were housed in cages in groups of four and allowed to acclimatize for 1 month, during which they were vaccinated and treated for ecto-parasites and endo-parasites as described by [5]. Vaccination against rabies and distemper, hepatitis, leptospirosis and Parvo virus were carried out using CANVAC $\AA$ rabies and CANVAC $® D H L P P$ vaccines respectively. They were also dewormed using mebendazole at $22 \mathrm{mg} / \mathrm{kg}$ body weight orally daily for 3 consecutive days and praziquantel at a dose rate of $20 \mathrm{mg} / \mathrm{kg}$ body weight orally at three months interval. They were washed once monthly with Amitrax ${ }^{\circledR}$ against ectoparasites. The animals were treated from time to time when the need arose and faecal and whole blood samples were routinely examined to ascertain that the dogs were free from any systemic infections. The dogs were fed once daily with boiled rice while water was provided ad lib. The kennels were also cleaned out once daily and disinfected with Izal. The dogs were then observed once daily for any vulval discharges, vaginal cytology, behavioural changes and haematological parameters to indicate the onset of the oestrus cycle.

\subsection{Sample Collection}

$5 \mathrm{ml}$ of blood was collected through cephalic vena puncture at various stages of the oestrus cycle (as indicated by behavioural changes and vaginal cytology). The blood was discharged into well - labelled ethylene diamine tetra-acetic acid (EDTA) coated sample bottles and taken to the laboratory for haematological studies. Total red blood cell (RBC), white blood cell (WBC), packed cell volume and haemoglobin concentration $(\mathrm{Hb})$ were determined according to standard procedures. Blood smears were made on clean, grease-free glass slides and stained with Giemsa stain. Total $\mathrm{RBC}$ and WBC were determined by the haemocytometer (Gelman - Hawsky Ltd, England) method. The PCV was determined by the microhaematocrit method, while $\mathrm{Hb}$ values were determined using the cyano-methaemoglobin method. The colorimeter reading obtained was compared with a standard curve and the corresponding $\mathrm{Hb}$ values were obtained. Data obtained were statistically analysed using the one way analysis of variance (ANOVA).

\section{Results}

All the dogs commenced their cycles between 8 months and 13 months of age ( $x=10.2$ months) as shown in Figure 1. It was also observed that dogs with smaller body frames attained puberty earlier than the bigger ones.

\subsection{Behavioural Pattern}

\subsubsection{Proestrus}

A couple of days before the onset of bloody discharge from the vulva of the bitches they were observed to be restless as indicated by frequent pacing in their cages, gazing at their hindquarters, low - sounding vocalization, intense licking of the vulva which was oedematous and exhuded with bright sero-sanguinous discharge, assumption of an alert stance with raised ears. These observations varied among the bitches in frequency and intensity. In addition some male dogs were seen around the compound were the bitches were caged, particularly at night (Photograph of bitch licking its vulva, vulva discharge).

\subsubsection{Oestrus}

At oestrus, it was observed that the volume of the vaginal discharge had reduced and changed in colour from reddish to straw-coloured or colourless. There was also restlessness, frequent micturition as well as flagging of the tail. During this stage, it was further observed that the vulvar oedema persisted but was soft to touch. This phase lasted between 7 and 11 days.

\subsubsection{Dioestrus}

At dioestrus, it was observed that the bitches showed no interest whatsoever in the male dogs and often barked at them; the vaginal discharges had reduced drastically, with the discharge becoming sticky and crusty in some cases, also the vulvar oedema had subsided and the vulva had gradually reduced in size with a pale mucosa.

\subsection{Haematology}

The haematology of the 16 dogs showed that the $\mathrm{PCV}, \mathrm{Hb}$ and $\mathrm{RBC}\left(40.2 \pm 1.31 \%, 14.0 \pm 0.43 \mathrm{~g} / \mathrm{dl}\right.$ and $5.8 \pm 0.24 \times 10^{9} / \mathrm{L}$ respectively) were lowest during dioestrus with the $\mathrm{PCV}, \mathrm{Hb}$ and $\mathrm{RBC}$ of the bitches in proestrus, oestrus and dioestrus showing no significant difference $(\mathrm{P}>0.05)$. However, the $\mathrm{MCV}$ was highest during anoestrus $(70.4 \pm 0.49 \mathrm{fl})$ and lowest during proestrus $(67.1 \pm 1.17 \mathrm{fl})$. There was also no significant difference $(\mathrm{P}>0.05)$ in the $\mathrm{MCHC}, \mathrm{MCH}, \mathrm{WBC}$ values 
across all the stages of the oestrus cycle.

Figure 1 shows the haemogram at each stage of the oestrous cycle with the MCV having the highest values followed by the PCV, MCHC, MCH, Hb, WBC and RBC.

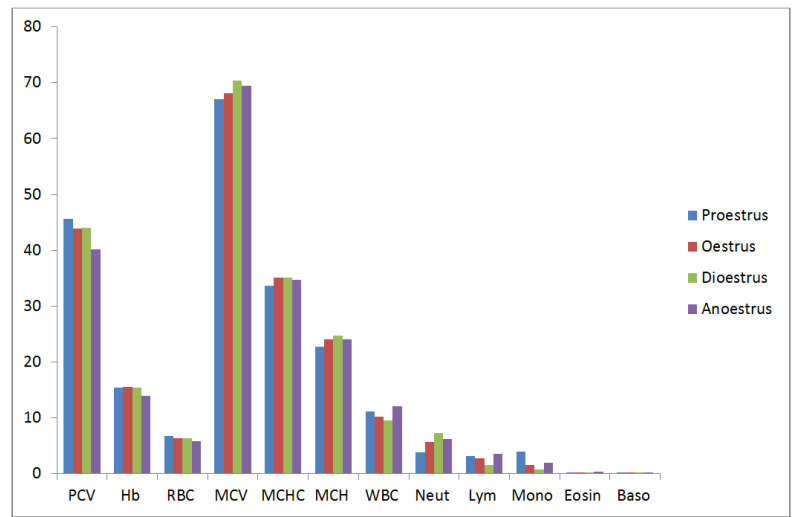

Figure 1. Haemogram of bitches at different stages of the oestrous cycle.

\subsection{Vaginal Cytology}

The microscopic views of the vaginal smears at various stages of the oestrous cycle are shown in Figures 2, 3, 4, 5, 6, 7 and 8 below:

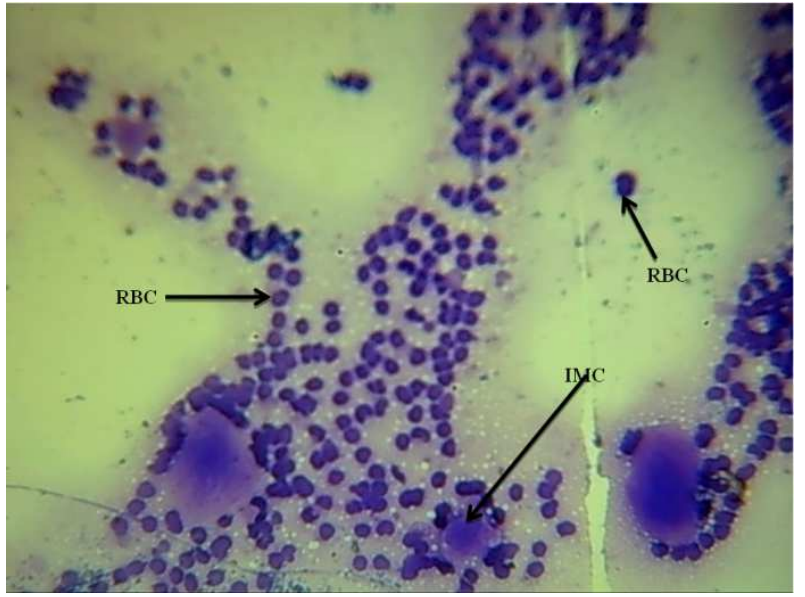

Figure 2. Proestrus: Black arrows showing red blood cell (RBC), Intermediate cell $(\mathrm{IMC}) \times 10 \mathrm{Mag}$.

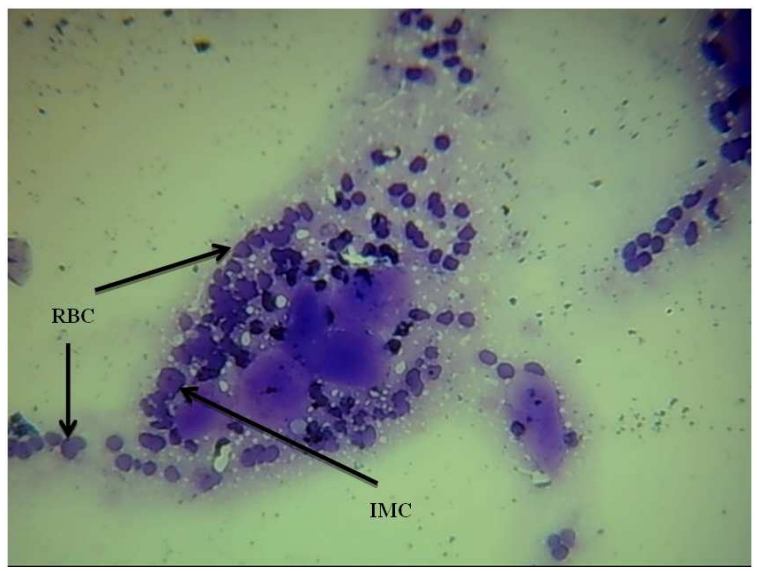

Figure 3. Proestrus $\times 40$ : black arrows showing red blood cells $(R B C)$ and intermediate cells (IMC).

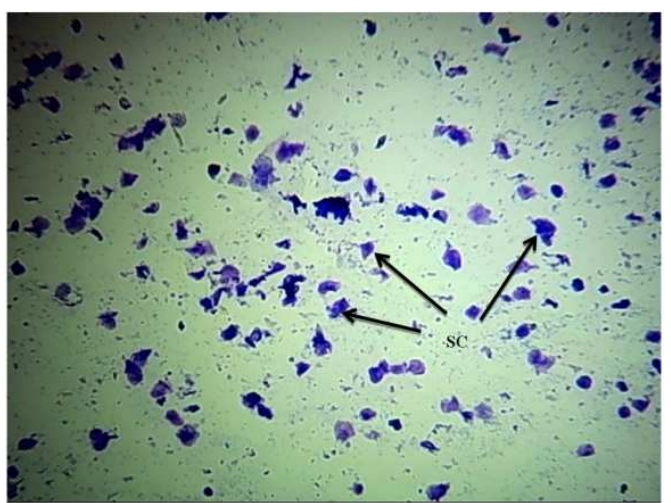

Figure 4. Oestrus $\times 10$ : black arrows showing superficial cells (SC).

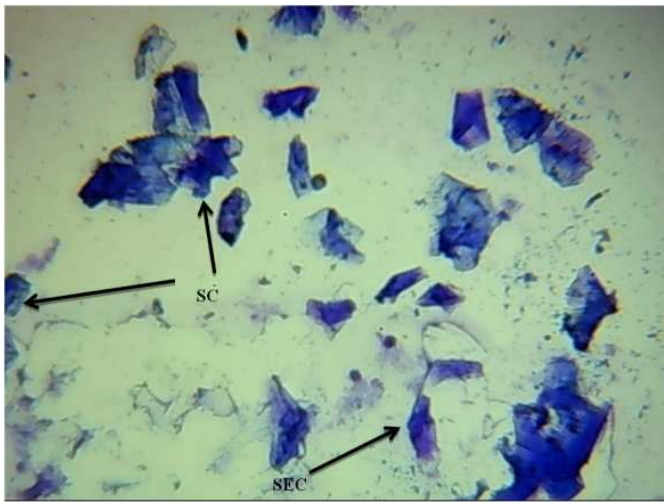

Figure 5. Oestrus $\times 40$ : black arrows showing superficial cells (SC).

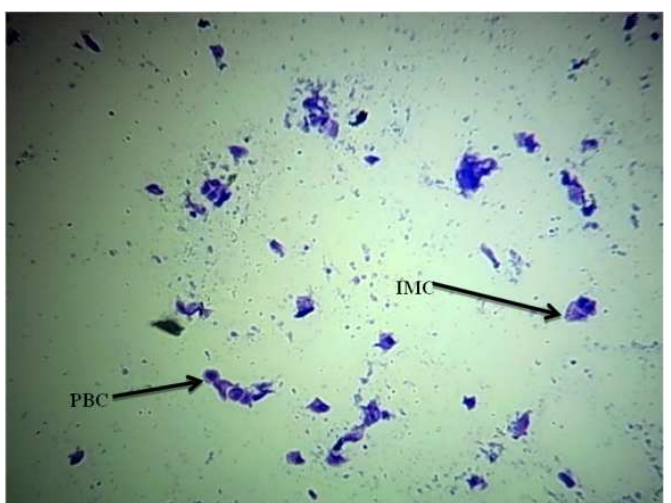

Figure 6. Dioestrus $\times 10$ : black arrows showing parabasal $(P B C)$ and intermediate cell (IMC).

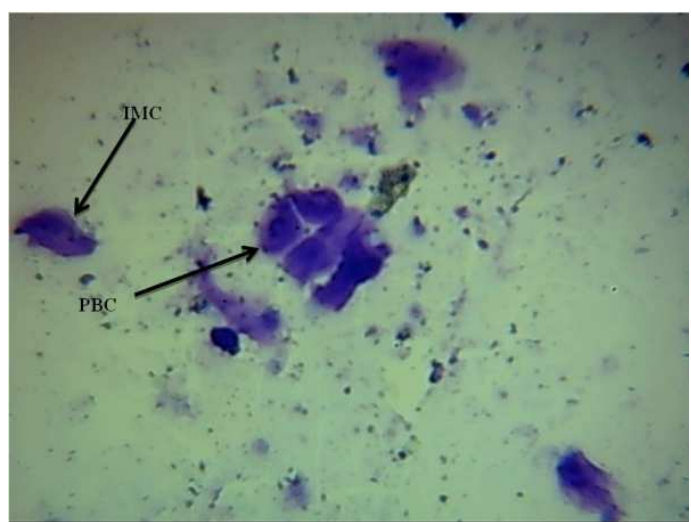

Figure 7. Dioestrus $\times 40$ : black arrows showing parabasal $(P B C)$ and intermediate cells (IMC). 


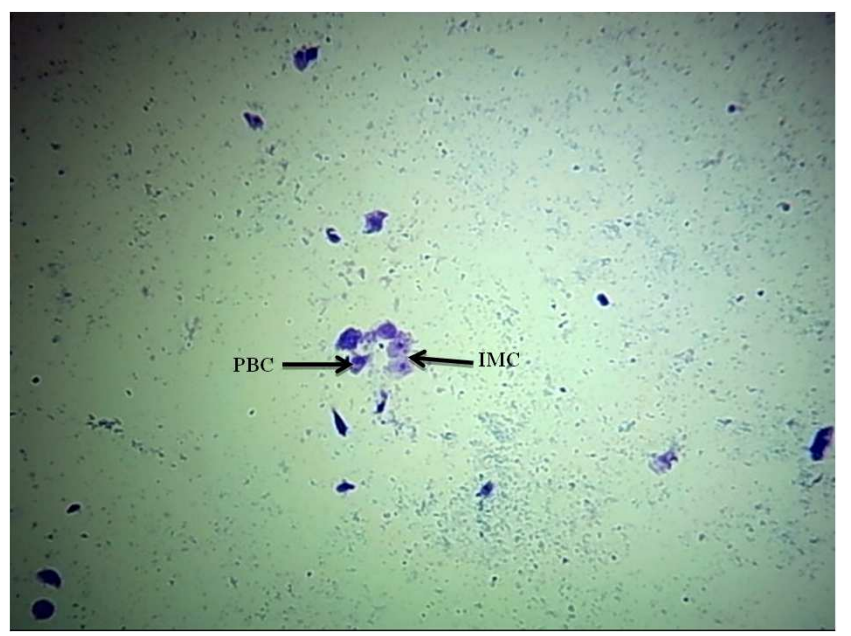

Figure 8. Anoestrus $\times 10$ : black arrows showing parabasal $(P B C)$, and intermediate cells (IMC) with reduced cellularity.

\section{Discussion}

\subsection{Behavioral Pattern}

The behavioural changes observed in the local bitches used for this study during proestrus include keen interest in male dogs, frequent micturition and flagging of the tail. These observations varied from bitch to bitch and had been reported by earlier workers $[10,14]$ in other breeds and by [5] in the Nigerian local bitch. The attraction but non-receptive behaviour exhibited by the bitches to the male dogs during proestrus has been attributed to the increasing levels of oestrogen which peaks at late proestrus along with the lowered amounts of follicle stimulating hormone (FSH) and luteinizing hormone (LH). Conversely, the refractory behaviour towards mating with diminished attraction to the male dogs during dioestrus can be attributed to the steady increase in the progesterone levels which gets to its peak before progressively declining in late dioestrus [15].

\subsection{Macroscopic Examination of the Vulva and Vagina}

The colour change in the mucous membrane of the vulva from deep pink (at proestrus) to very pale (at anoestrus) corresponds favourably with reports from [5] and the changes in the size of the vulvar lips through the four stages of the oestrous cycle was similar to the findings reported by $[8,10$, 16] for other breeds of bitches and [5] for Nigerian local bitches. The quantity, colour and consistency of the vaginal discharge throughout the oestrous cycles in all the bitches used for the study were consistent with reports by $[8,14,17]$ in other breeds of bitches and [5] in the Nigerian local bitch. The dark pink colour of the vulva during proestrus is due to hyperaemia [18] while the paleness of the vulva during dioestrus is due to the reduction of blood flow to the reproductive organs. The increase in the size of the vulva during proestrus and oestrus is due to the hormonal activity of oestrogen which allows the increment of the vulvar and vaginal epithelial layers presumably to provide protection to the mucosa during copulation. The reduction and total absence of oedema in the vulva and vagina at dioestrus is as a result of the rising progesterone levels acting synergistically with the declining oestrogen levels at these stages [15, 19]. The serosanguinous vaginal discharge observed at proestrus is a direct effect of oestrogen on the glandular epithelium of the uterus, promoting swelling, increased vascularity of the uterine mucosa, allowing for the junctions between the capillary endothelial cells to leak and permit the passage of RBCs into the uterine lumen which is usually discharged vaginally after passage through the cervix $[5,11,18,20,21]$. The straw-coloured vaginal discharge observed at oestrus could be as a result of reduction in the presence of red blood cells in the uterine secretions due to the decreasing levels of oestrogen.

\subsection{Haematology}

The haemogram of the bitches observed in this study was comparable to the values, PCV $46.10 \pm 4.16 \%, \mathrm{Hb}$ $15.39 \pm 1.99 \mathrm{~g} / \mathrm{dl}$ reported by [22] for Nigerian local dogs.

The result of this study also shows that the $\mathrm{PCV}, \mathrm{Hb}$ and RBC values were lowest during dioestrus which is at variance with earlier reports by [5], who reported thatthese values were lowest at proestrus. There was a significant difference $(\mathrm{P}<0.05)$ in the $\mathrm{PCV}, \mathrm{Hb}$ and $\mathrm{RBC}$ values, which were slightly elevated during proestrus. However, there was no significant difference $(\mathrm{P}>0.05)$ in $\mathrm{PCV}, \mathrm{Hb}$ and $\mathrm{RBC}$ at oestrus and dioestrus.

The study also showed that the RBC counts were reduced during diestrus and increased gradually during proestrus, with the lowest value recorded during oestrus, although with no significant difference $(\mathrm{P}>0.05)$, which is at variance with reports by $[5,23]$

The PCV, $\mathrm{Hb}$ and $\mathrm{RBC}$ values for all the stages of the oestrous cycle compares favourably with the reference ranges $37-54 \%, 13.0-19.0 \mathrm{~g} / \mathrm{dl}$ and $5.4-7.8 \times 10^{12} / \mathrm{L}$ respectively [24]

The WBC values $\left(9.6 \pm 0.86\right.$ to $\left.12.1 \pm 0.73 \times 10^{9} / \mathrm{L}\right)$ were lower than (18.52 \pm 2.51$)$ reported by [22] but in agreement with $\left(9.7 \pm 2.84\right.$ to $\left.12.5 \pm 2.1 \times 10^{3} / \mu \mathrm{L}\right)$ reported by [23]

The study showed an increase in WBC during proestrus $\left(11.1 \pm 0.67 \times 10^{9} / \mathrm{L}\right)$ and oestrus $\left(10.2 \pm 1.30 \times 10^{9} / \mathrm{L}\right)$ with a slight decrease during dioestrus $\left(9.6 \pm 0.86 \times 10^{9} / \mathrm{L}\right)$ and a later increase at anoestrus $\left(12.1 \pm 0.73 \times 10^{9} / \mathrm{L}\right)$, a pattern similar to what was reported by [23]. The WBC values for all the stages of the oestrous cycle showed no significant difference $(\mathrm{P}>0.05)$.

The leucocytosis observed at oestrus and dioestrus could have been due to neutrophilia while the leucocytosis observed at proestrusmight have been due to neutrophilia, lymphocytosis and monocytosis.

The observed neutrophilia may be as a result of inflammation, bacterial infection, or acute stress [25]. The observed lymphocytosis may be due to parasitic infestation, neoplasia or stress response [26]. Monocytosis may be due to chronic diseases, especially chronic inflammation, or neoplasia [26].

The WBC values for all the stages of the oestrous cycle however compares favourably with the reference range 6.0-17.0 $\times 10^{9} / \mathrm{L}$ along with the differential absolute WBC values [24]. 


\subsection{Vaginal Cytology}

The red blood cell (RBC) and intermediate cells observed at proestrus in this study compare favourably with earlier findings by [5], who reported that red blood cells, parabasal cells as well as (small) intermediate cells were observed at this stage but is not entirely in agreement with those of [11] and [15] where superficial cells (in addition to red blood cells, intermediate cells and parabasal cells) were reported to be found at this stage also. At oestrus, superficial epithelial cells were observed, which compares favourably with the findings of $[5,11,15,27]$. The aforementioned authors however reported the presence of red blood cells (in few numbers) at oestrus. The parabasal and intermediate cells observed at dioestrus in this study compares favourably with the findings of $[5,11,15]$ but not entirely as it was further reported the presence of few white blood cells (neutrophils) along with the parabasal and intermediate cells at dioestrus. At diestrus, it was observed that the cellular population was low; however, parabasal and intermediate cells were seen in the smear which compares favourably with reports by [11] and [27] but not entirely with [5] who reported the presence of only parabasal cells. The changes in the cell types observed may be as a result of the hormonal changes at each stage of the oestrous cycle.

\section{Conclusion}

Observations from this study have shown that the oestrus cycle of the Nigerian local bitches in Gwagwalada metropolis, Abuja compares favourably with other foreign and local bitches.

\section{Recommendations}

Several factors such as age, sex, breed, stress, nutrition, management systems, health status, parasitic infestation, etc. can affect the haematological parameters of Nigerian local dogs, hence their haematology shouldn't be used alone as a yardstick for the investigation of the various stages of the oestrous cycle. It is important to combine the behavioural patterns, macroscopic examination of the vagina and vulva, vaginal cytology along with the haematological parameters for proper investigation of the oestrous cycle in order to achieve optimum breeding and regulation of canine reproductive activity. There is also need for the Nigerian local bitches to be properly catered for (like the foreign breeds) so as to ensure optimum breeding and production.

\section{References}

[1] Zeuner, F. E. (1963): A history of domesticated animals. Hutchinson \& Co. Ltd, London. 560pp.

[2] Epstein, H. The origin of the domesticated animals of Africa. Africana Publ. Corp., New York, London, Munich, 1:1-573, 2:1-719, 1971.
[3] Oyeyemi M. O; Akusu M. O. \& Ola-Davies, O. E (2000). Effect of successive ejaculations on the spermiogram of West African dwarf goats (Capra hircus L.). Veterinarski arhiv, Vol. 70 No. 4, 215-221.

[4] Pfaffenberger, C. J.: Scott, J. P. (1959): The relationship between delayed socialization and trainability in guide dogs. J. Genet. Psychol. 95, 145-155.

[5] Oluwatoyin O. Ajala, Fayemi, O. E., and Oyeyemi, M. O. 2012. The oestrous cycle of the Nigerian local bitch. Global Veterinaria 8.6: 574-582.

[6] Mutembei, H. Mutigaa, E. R and Tsuma, V. T. (2000) A retrospective study on some reproductive parameters of German shepherd bitches in Kenya. Journal of the South African Veterinary Association, 71 (2): 115-1.

[7] Delemarre-van de Waal H. A., van Coeverden S. C. C. M., Engelbregt M. J. T (2002): Factors affecting onset of puberty. Horm Res 2002; 57 (suppl 2): 15-18 doi:10.1016/j.anireprosci.2010.08.028

[8] Davol P. A (2000): Canine reproduction Part 1: Reproduction and the bitch. Retrieved 19/09/2016, 07:47pm from $\mathrm{http}: / / w w w . l a b b i e s . c o m /$ reproduction.htm

[9] Dewey T. and Bhagat S. (2002): Canis Inpus familiaris. Animat. Diversity Web. Retrieved 14/02/2016, 01:56pm from http://www.animaldiversity.org/accounts/Canis_lupus_familiaris/

[10] Nelson R. N. and Couto C. G. (2003): Small Animal Internal Medicine 3 Ed. Mosby 11830 Westline Industrial Drive St. Louis Missouri 63146: 847-933.

[11] Pretzer S. D (2009): Canine oestrous cycle: Abnormalities of the Canine Estrous Cycle: A Review. Retrieved 29/03/2016, 07:01pm from http://www.uskbtc.com/about-kerries/healthgenetics/canine-oestrous-cycle/

[12] Balogun O. (2001): The Federal Capital Territory: A Geography of its development. University Press, Ibadan, Nigeria.

[13] Tong S. and Donald K. (2002). Climate Variability and Disease Virus Transmission. Journal of Epidermiology Community; 56: 617-621.

[14] Beimborn K. S., Tarpley H. L., Bain P. J. and Latimer K. S. (2003): The canine estrous cycle staging using vaginal cytological examination.

[15] Davidson B. P (2013): Dogs. The Merck Veterinary Manual. Retrieved 20/09/2016, 10:34am from

http://www.merckvetmanual.com/mvm/management_and_nut rition/management of reproduction_small animals/breeding management_of_small_animals.html

[16] Correa J. E (2002): Canine breeding and reproduction. Food and Animal Science. Albama, A and M University. Albama cooperative extension system. UNP-52. Retrieved 20/09/2016, 01:43pm from http://www.aces.edu

[17] Wright P.J. and Chu Po-yin, (2001): The oestrous cycle of the bitch: Oestrus induction and suppression. Retrieved, 28/01/2016, 06:45pm from http://www.greyhoundvet.co.uk/downloads/AGVAOL.HTM

[18] Noakes D. E. Parkinson T. J. and England G. C. W (2009): Veterinary Reproduction and Obstetrics, $9^{\text {th }}$ ed. Saunders Company. Chap. 1, Pg 6. 
[19] Blendinger K. (2007): Physiology and pathology of the oestrous cycle of the Bitch. Proceedings of the SCIVAC Congress, Rimini, Italy.

[20] Phemister R. D., Holst P. A., Spano J. S., Hopwood M. L., (1973): Time of ovulation in the Beagle Bitch. Biol Reprod, 8, 74-82 [PubMed: 4734806].

[21] Wildt D. E, Panko W. B, Chakraborty P. K, Seager S. W (1979): Relationship of serum estrone, estradiol-17 $\beta$, and progesterone to $\mathrm{LH}$, sexual behavior and time of ovulation in the bitch. Biol Reprod. 20: 648-658.

[22] Bobade P. A., Oduye O. O., Helen O. and Aghoma O. (1985): Haemogram of clinically normal dogs with particular reference to local (Nigerian) and German shepherd dogs. Nigerian Veterinary Journal, 14(1):7-11.

[23] Mshelia G. D., Amin J. D and Chaudhary S. U. R (2005): Haemogram of Nigerian mongrel bitches at different stages of the reproductive cycle. Pakistan Vet. J., 25(1).
[24] Anonymous (2014): Canine Haematology - Wiki Vet English. Retrieved 18/09/2016, 01: 23 pm from http://en.wikivet.net/Canine_Haematology

[25] Whitbread T. J. (2015): Clinical Hematology. The Merck Veterinary Manual. Retrieved 18/09/2016, 06: 32 pm from http://www.merckvetmanual.com/mvm/clinical_pathology_an d_procedures/diagnostic_procedures_for_the_private_practice laboratory/clinical_hematology.htm

[26] Avery A. C. and Avery P. R (2007): Determining the significance of persistent lymphocytosis. Vet. Clin. North Am Small Anim Pract 37(2): 267-282.

[27] Anonymous (2016c): The Canine Estrous Cycle. Aquila Kennels. Alaskan Malamutes. Retrieved 20/09/2016; 07: 42pm from http://www.aquilakennels.com/estrous_cycle.php 